\title{
Escola Padre Benjamim Salgado, Joane
}

\author{
C O N D U I D A P R CARLOS FOLHADELA S I M Õ S
}

Pretende-se neste espaço continuar a dar conhecimento do que se vai fazendo, em prol da Química, nas escolas deste país. A deslocação à Escola Secundária Padre Benjamim Salgado, em Joane, Vila Nova de Famalicão, foi motivada pela conquista do prémio "Ciência na Escola", promovido pela Fundação Ilídio Pinho, com o projecto "Quimicando - Ciência e Tecnologia na Alimentação".

Um motivo para visitar a escola e conversar com a Dr. ${ }^{\text {a Fer- }}$ nanda Araújo (FA), coordenadora do projecto e com o Dr. Alfredo Mendes (AM), Presidente do Conselho Executivo.
Dr. Alfredo Mendes (AM), agradecia-lhe que nos apresente a Escola Secundária Padre Benjamim Salgado.

AM - A escola está a funcionar há vinte anos. É uma escola que apesar de secundária possui, neste ano escolar, 15 turmas do $3 .^{\circ}$ ciclo e 25 turmas do ensino secundário. Em termos de ensino secundário predominam nos cursos de carácter geral, os cursos científico-natural. Há uma grande procura deste tipo de oferta.

A escola tem condições para dar resposta a tantos alunos?

AM - Sim. Temos a escola bem equipada a fazer face à procura. A escola foi ganhando, nestes últimos anos, uma cultura em termos de trabalho prático e experimental na área das ciências, de grande valor e que neste momento está consolidado. Faz parte integrante da cultura da Escola.

Posso depreender que essa cultura implica o apoio a projectos que visem o desenvolvimento de novas práticas e o enriquecimento dos alunos?

AM - Apoiamos e acompanhamos projectos realizados quer este ano, quer em anos anteriores e preocupamo-nos, sobretudo, em dotar a escola das condições materiais para que possam existir condições para o desenvolvimento de projectos quer no âmbito da química, da física e de outras ciências.

...o que não deve ser fácil...

AM - Não, não é. Nesta tentativa de meIhorar as condições, temos conseguido, embora nem sempre com a rapidez desejada, o apoio da DREN, para a remodelação das instalações e temos feito um forte investimento na aquisição de material e aparelhagem necessários a esse tipo de actividades.

Se a escola fosse exclusivamente secundária, as condições proporcionadas aos alunos seriam outras ou por outro lado considera benéfica esta convivência entre alunos de faixas etárias diferentes?

AM - Tendo em conta o meio, acho que se fosse só secundária pouco ou nada acrescentaria ao que é neste momento. É importante e penso que até em termos de política educativa já se constatou isso, que as escolas secundárias não sejam puramente do ensino secundário pois é importante que convivam, integrem e estudem no mesmo espaço alunos de escalões etários diferentes e de níveis de ensino igualmente diferentes. Isso proporciona e contagia um determinado tipo de actividades escolares que provavelmente não se verificariam se a escola tivesse outro cariz.
Dr. ${ }^{a}$ Fernanda, como surgiu e ideia de concorrer com um projecto da área alimentar?

FA - A ideia surgiu a partir da vivência diária, nomeadamente da vivência familiar. Observamos diariamente jovens e crianças a consumir guloseimas e alimentos muito coloridos: pastilhas elásticas, rebuçados, "pintarolas", gomas, chupa-chupas, gelatinas, bolos ... disponíveis no mercado em todos os feitios, aromas e cores. A finalidade do trabalho era que eles próprios averiguassem 0 perigo que o consumo excessivo de alimentos coloridos pode acarretar para a sua saúde.

Acredito que a equipa que coordenou se sinta particularmente satisfeita com a conquista do prémio. Esperavam alcançá-lo?

FA - O objectivo do trabalho não tinha em vista o prémio classificativo, mas sim o aspecto educativo que lhe estava subjacente: alertar a comunidade para a existência dos aditivos nos alimentos e suas consequências ao nível da saúde em termos toxicológicos e de reacções alérgicas.

...mas o prémio é também a recompensa do trabalho efectuado...

FA - Claro! 
figura 1 Alunos da Escola Secundária Padre Benjamim Salgado envolvidos no projecto Quimicando.
Dr. Alfredo, o prémio alcançado, 7500 euros, será investido na dotação de melhores equipamentos para estas áreas?

AM - Sim, claro. Será para aquisição de equipamentos e para apoiar mais projectos. Creio que o próximo será no âmbito da Física assim como para outro em que sejamos convidados ou desafiados a participar.

\section{Em que consistiu o projecto?}

FA - Consistiu em extrair corantes de guloseimas, utilizando lã de ovelha não tratada e a sua identificação por cromatografia em camada fina e espectroscopia de UV/Vis. O processo seguinte era avaliar a sua nocividade e averiguar se o rótulo do produto o identificava. De referir que verificamos irregularidades em vários rótulos e encontramos produtos sem rótulo. Pretendia-se ainda que os alunos com os conhecimentos adquiridos promovessem acções de sensibilização (teóricas e práticas), abertas à comunidade escolar, família e comunidade em geral.

... mas isso deve ter envolvido muitas horas de trabalho...

FA - Sim, de facto todo o projecto foi concebido e realizado em horas extracurriculares quer por parte dos professores quer por parte dos alunos e devo referir que a parte experimental é muito morosa.

...à noite?

FA - E não só, ao sábado também. De facto toda a parte de concepção do pro-

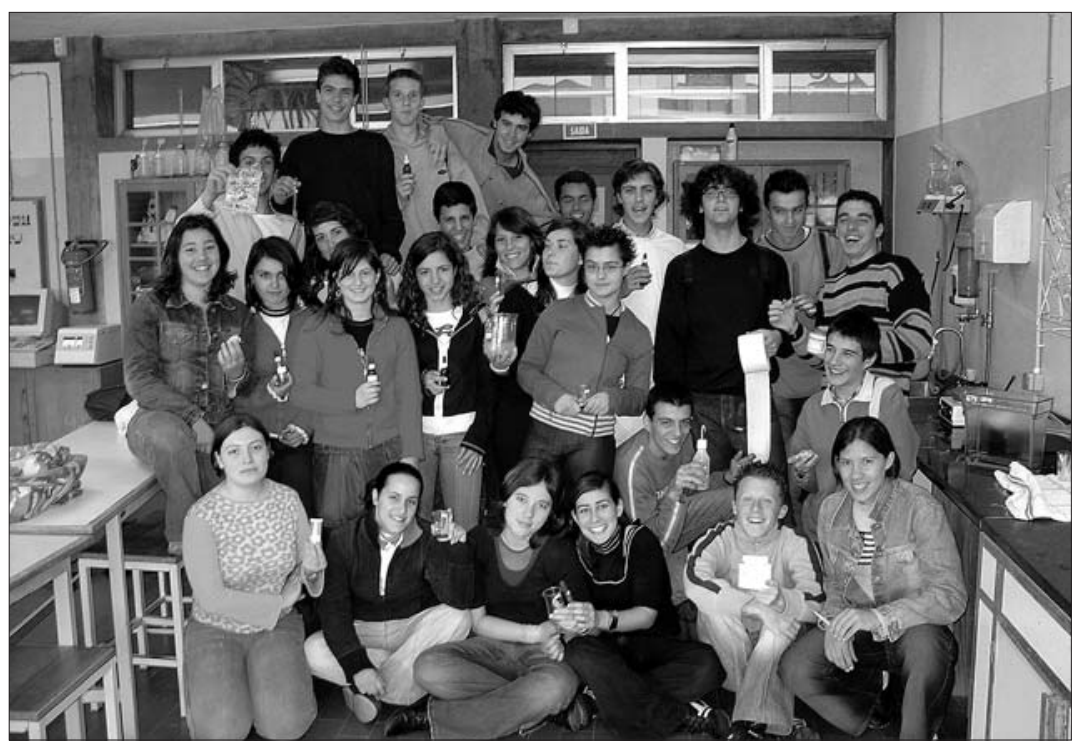

jecto, relatórios, artigos jornalísticos, acções de sensibilização ... foram realizadas em horas subtraídas ao lazer e à família.

O contágio de que falava à pouco também se estende à comunidade?

AM - Temos tido algumas experiências, como foi exemplo o projecto deste ano, com sessões abertas ao mundo exterior e temos tido sempre respostas positivas.

A comunidade teve conhecimento do trabalho realizado e do prémio conquistado?

FA - Sim já que o mesmo foi objecto de ampla cobertura da comunicação social (jornais, rádio e televisão). Para além disso um dos objectivos do projecto era a sensibilização da comunidade, o que foi conseguido com a realização de acções de sensibilização que se revelaram fortemente mobilizadoras e participativas.

Qual o grau de satisfação dos alunos quer na participação no projecto quer com os resultados alcançados?

FA - Muito grande. Foi demonstrado pelo entusiasmo, empenho e participação na implementação do projecto. De salientar que de um projecto feito para alunos, rapidamente se transformou num projecto dos alunos já que os mesmos se revelaram um elemento essencial na sua concretização.

A ESPBS é também conhecida por diversas acções na área do ambiente...
AM - Sim, é verdade. Penso que se tem feito um bom trabalho em termos ambientais de exploração dos recursos da região, de detecção de focos de poluição e de lançamento de campanhas de sensibilização sobre essa matéria. Desenvolveram-se também projectos na área dos 3R's. Para além do mais, tem sido prosseguida uma campanha de separação de resíduos dentro da própria escola de modo a sensibilizar os alunos e a contribuir para que essas práticas extravasem os muros da escola.

Acredita que estes concursos promovidos por instituições públicas, ou privadas como neste caso, podem contribuir para a motivação e empenho dos alunos no âmbito da Química?

FA - Vivamente. É sempre bom haver motivos que proporcionem situações de aprendizagem extracurriculares e que permitam desenvolver o gosto pela ciência, nomeadamente pela Química.

Que mais gostaria de ver surgir que pudesse contribuir para esse desígnio?

FA - Que outras instituições, públicas ou privadas, contribuíssem de algum modo para o desenvolvimento da ciência e consequentemente para o desenvolvimento do país. É importante este tipo de apoio e incentivo às escolas.

AM - Há alguns anos, participamos e também fomos premiados num concurso, então organizado por uma companhia de seguros, em que o trabalho apresentado, sistematizava os diversos projectos realizados na área-escola e 


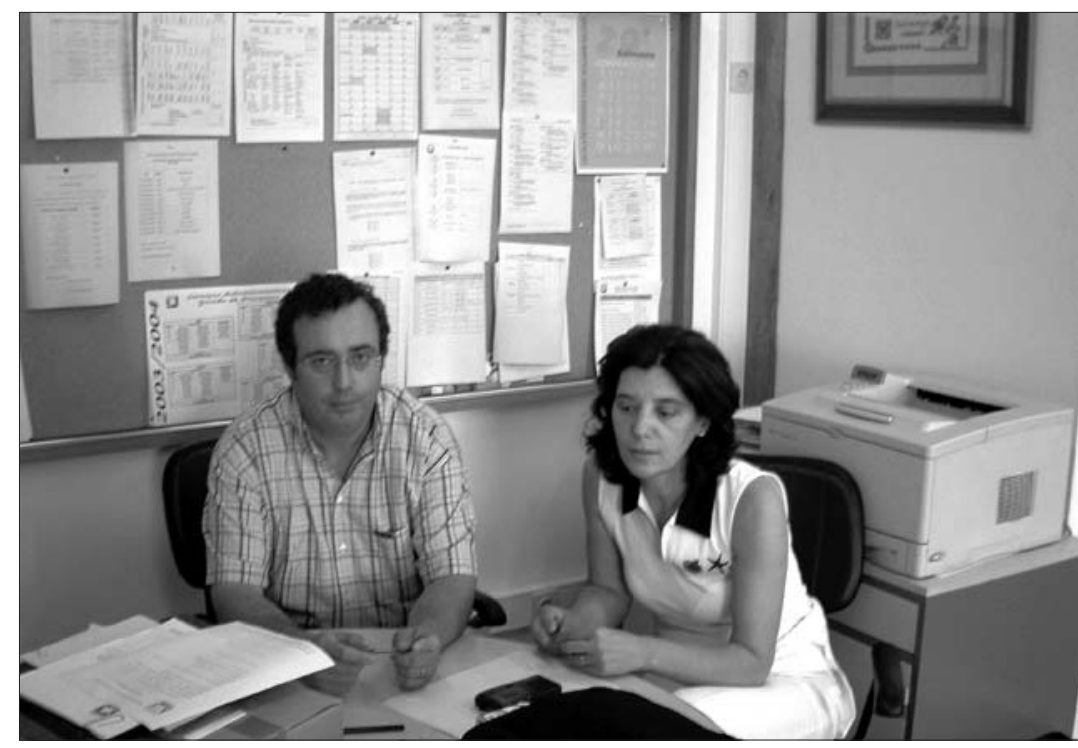

versava temas como ambiente, higiene e segurança no trabalho, num único tema :"Saúde".

Foi a primeira vez que aderiram a uma participação desta natureza?

FA - Foi a primeira vez que aderimos a um projecto desta natureza que tem um carácter selectivo e que premeia a qualidade, no entanto participamos em outro tipo de programas, nomeadamente no Galileu e no Ciência Viva.

E que pensam do desaparecimento do "Ciência Viva"?

FA - Lamento, já que ele proporcionava o desenvolvimento de projectos e o apetrechamento dos laboratórios das escolas, contribuindo grandemente para o desenvolvimento do estudo experimental das ciências.

AM - Foi pena. O Ciência Viva permitiu que vários professores apresentassem candidaturas e desenvolvessem projectos. Com o fim desses apoios obviamente que se torna tudo mais difícil. Durante vários anos apresentamos duas a três candidaturas anuais, em diversas áreas. Revestiam-se de grande significado em termos educativos e também serviam, como sabe, para aumentar o apetrechamento da escola.

Considera então importante o trabalho laboratorial no ensino secundário...

FA - Considero que o trabalho laboratorial não só é importante como deve ser incrementado. Acredito que aprender experimentando é uma pedagogia que adquire maior pertinência numa escola para todos e numa sociedade que valoriza, cada vez mais, o conhecimento activo e pró-activo, por oposição ao conhecimento inerte e apenas memorizado.

Acredita que os novos programas de $10 .^{\circ}$ e $11 .^{\circ}$ anos, o de $12 .^{\circ}$ ainda se desconhece, irão permitir que os alunos terminem o secundário com as mesmas competências no trabalho experimental?

FA - Creio que a não existência das disciplinas técnicas são um forte revés nessa situação. No entanto e apesar de algumas dificuldades inerentes à mudança gostaria que o resultado final fosse o mesmo.

Que feed-back tem da implementação dos novos curricula?

AM - Como deve calcular este ano foi extremamente complicado: com muitas incertezas, inclusive e sobretudo por parte da Administração Central, com algumas ideias que por vezes, nem sempre eram realizadas e com uma grande falta de planeamento a médio prazo. Falta saber o que irá acontecer a estes alunos que terminaram o $10 .^{\circ}$ ano quando chegarem ao $12 .^{\circ}$. Como irão ser avaliados? O que thes vai ser pedido? Os professores face a esta indefinição do Ministério, face a esta falta de apoio e de orientações concretas, tentaram fazer o melhor possível. Tentaram realizar com os alunos as actividades que consideraram importantes no sentido de assegurarem o cumprimento dos programas, figura $20 \mathrm{Dr}$. Alfredo Mendes (esq.)

Presidente do Conselho Executivo da ESPBS e a Dr. ${ }^{a}$ Fernanda Araújo (dir.) coordenadora do projecto Quimicando.

sob pena de, nalguns casos, não poderem realizar algumas daquelas para que os próprios programas apontavam. Acabou por se ter de abdicar de actividades em função dos conhecimentos.

Mas voltando aos projectos, que outros foram ou são realizados na escola?

FA - Síntese de polímeros utilizados no quotidiano bem como o impacto que estes produzem no ambiente. Identificação de polímeros mais utilizados no diaa-dia e a produção de alguns materiais poliméricos. Alertar para a importância da reutilização/reciclagem e eliminação dos diversos materiais, incutindo nos jovens a responsabilidade no tratamento desses materiais.

O Quimicando envolveu também a produção de um CD e de um DVD. Foi um trabalho interdisciplinar com o grupo de informática?

FA - Foi. Tivemos ainda a colaboração do grupo de biologia no tocante às questões alimentares.

A escola aposta nas novas tecnologias de informação. Essa aposta dá maior visibilidade à escola?

AM - É uma conclusão que não tiro, ou não tenho elementos para assim concluir. Sei é que temos uma política para apetrechar a escola com equipamento informático e multimédia que irá ser continuada. São um recurso importante para apoio a diversas actividades. É um projecto em desenvolvimento e expansão. Tínhamos algumas limitações técni- 


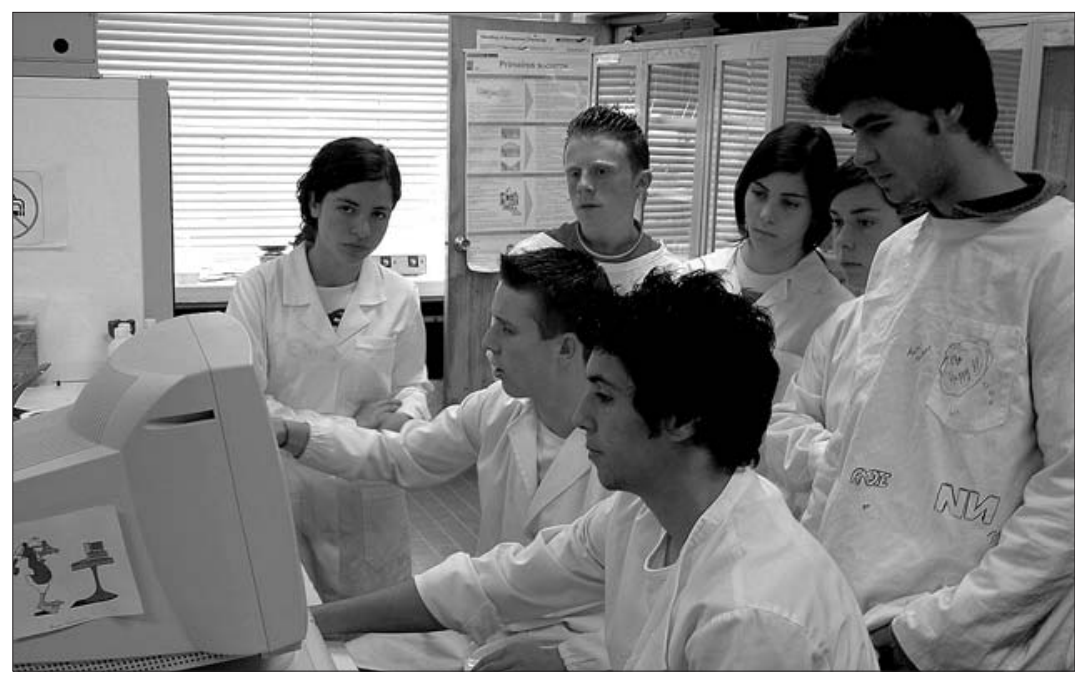

cas que vão ficar resolvidas e vamos poder equipar os laboratórios com projectores multimédia, ligações à internet para que os professores possam utilizar esses recursos de modo eficaz e conveniente. Queremos levar a cada sala a rede interna e os terminais. Vamos começar pelos laboratórios e salas específicas de algumas disciplinas e estender ao resto da escola num futuro, que desejo, não longínquo.

É uma aposta significativa na criação de mais e melhores condições...
AM - Sim, a disponibilidade e o apoio do Conselho Executivo é para todos os grupos disciplinares e para todos os professores. É óbvio que nalgumas áreas há a possibilidade ou até a necessidade de fazer uma aposta diferente já que as metodologias são também mais exigentes nos recursos. O importante para além de criar as condições materiais é também criar as condições para que exista predisposição da parte dos professores para desenvolver esses trabaIhos. É nisso que apostamos.
Já participaram nas Olimpíadas de Química?

FA - Não

Porquê? Desconhecimento, desinteresse dos alunos...?

FA - Não por desconhecimento, mas porque no âmbito do nosso grupo disciplinar ainda não houve uma atitude de dinamização dos alunos para a participação nas Olimpíadas de Química.

\section{Actualidades Científicas}

\section{Óxidos tipo Fulereno}

Os óxidos tetraédricos, como os silicatos e os aluminatos, têm suscitado um grande interesse, devido ao seu potencial para aplicações em várias áreas, desde a catálise, a permuta iónica e os peneiros moleculares, até à termo e fotoluminescência. Apesar do seu carácter tetraédrico, nunca se tentou relacionar a sua estrutura com a de diferentes formas de carbono, como por exemplo, os fulerenos. Recentemente, investigadores Franceses do laboratório CRISMAT, do centro nacional de investigação científica de Caen, sintetizaram pela primeira vez um óxido tipo fulereno, constituído por esferas de $\mathrm{Al}_{84}$ (Hervieu et al., Nature Materials, (2004) 3, 269). A grande similaridade desta estrutura com a do isómero $\mathrm{D} 2 \mathrm{~d}$ dos fulerenos $\mathrm{C}_{84}$ abre o caminho para a exploração de outros possíveis membros desta série, variando o tamanho das esferas $\mathrm{Al}_{\mathrm{n}}$ e o seu modo de ligação, por alteração da natureza e quantidade dos catiões alcalino-terrosos relativamente às espécies de alumínio tetraédricas, considerando também a possibilidade de introduzir outras espécies tetraédricas nas posições dos alumínios, como Si, Ge, Ga, Fe e outros, bem como outros catiões ou aniões dentro da esfera $\mathrm{Al}_{\mathrm{n}}$. Como consequência, estes materiais deverão ser potenciais para várias propriedades e aplicações, desde a fotoluminescência e termoluminescência, ao magnetismo, propriedades ópticas não lineares e catálise.

Helder Gomes

\section{Novos materiais para cultura celular}

A utilização de novos materiais, cuja estrutura é desenvolvida e adaptada à função que desempenham, é cada vez mais frequente. Com este intuito, um grupo de investigadores em Israel desenvolveu um novo tipo de material para suportar o crescimento de células que permite a substituição das convencionais placas de petri revestidas por poliestireno (Zolkov et al., J. Mat. Chem. (2004) 14, 2200). O novo material é obtido através da técnica sol-gel, sendo composto por filmes híbridos de sílica, contendo L-lisina. Foram testadas diferentes composições, tendo sido verificado que a hidrofobicidade da superfície do filme é um factor muito importante para a adesão e posterior crescimento das células testadas.

Dado o sucesso desta primeira abordagem, os investigadores pretendem o desenvolvimento de novos filmes adaptados a diferentes tipos de cultura, usufruindo da versatilidade da técnica proposta no que diz respeito à inclusão de diferentes grupos funcionais (adaptado de Chemical Science (2004) 1, C45).

Marcela Segundo 